Biochimica et Biophysica Acta, 363 (1974) 249-260

c. Elsevier Scientific Publishing Company, Amsterdam - Printed in The Netherlands

BBA 76713

\title{
ACTION OF INSULIN ON AMINO ACID UPTAKE BY THE IMMATURE RAT UTERUS IN VITRO
}

TETSURO MOHRI, HARUO KITAGAWA and THOMAS R. RIGGS*

Department of Biological Chemistry, University of Michigan, Ann Arbor, Mich. (U.S.A.) and Department of Biochemical Pharmacology, Faculty of Pharmaceutical Sciences. University of Chiba, Chiba (Japan)

(Received March 19th, 1974)

\section{SUMMARY}

1. The uptake of $\alpha$-aminoisobutyric acid by the immature rat uterus was studied kinetically in vitro, and the stimulatory action of insulin on uptake was characterized. Other amino acids were also studied for comparison.

2. $\alpha$-Aminoisobutyric acid uptake was increased if the uteri were pretreated with insulin for $20 \mathrm{~min}$ or more. The $V$ of the saturable transport was increased by $19 \%$ by insulin treatment, but no $K_{\mathrm{m}}$ change was apparent.

3. Puromycin eliminated the insulin action on $\alpha$-aminoisobutyric acid uptake within 40 min of treatment.

4. The effect of insulin on $\alpha$-aminoisobutyric acid uptake was abolished either by a preliminary 10 -min incubation of the uterus with a high concentration $(1 \mathrm{mM})$ of $N$-ethylmaleimide; or by incubation, concurrent or subsequent, with a low concentration of $N$-ethylmaleimide $(0.05 \mathrm{mM})$.

5. The uptake of L-proline, L-methionine and glycine, but not that of Lleucine or L-valine, was also increased by insulin treatment. Insulin acted on a $\mathrm{Na}^{+}$dependent uptake; it was without effect on the $\mathrm{Na}^{+}$-independent uptake of either $\alpha$-aminoisobutyric acid or methionine. The evidence suggests that insulin acts on the A system of amino acid transport in the uterus.

\section{INTRODUCTION}

Insulin has been shown to increase the transport of a number of amino acids into various muscle tissues in vitro [1-12]. Its effect on the uterus has not, however, been previously tested. This latter tissue is of interest because its transport of the short-chain, more polar, amino acids in vitro can be increased by as much as $100 \%$ by the injection of estradiol- $17 \beta$ into rats before the uteri are removed [13]. These and other characteristics of the uptake suggest that the steroid hormone

* Address reprint requests to: Dr T. R. Riggs, Department of Biological Chemistry, The University of Michigan, Ann Arbor, Mich. 48104, U.S.A. 
acts on the A system of transport in this tissue [13-15]. Insulin, on the other hand, also acts on the A system, at least in the rat diaphragm [16]. It is of special interest, therefore, to determine if insulin also affects the A system in the uterus; and, if so, to compare the actions of the two hormones on this system.

The present paper reports results showing that insulin can increase transport by the uterus of the same amino acids that are affected by estradiol. Some of the characteristics of this stimulation by the peptide hormone are also presented, and some implications of the mechanism of hormone action on transport are discussed.

\section{MATERIALS AND METHODS}

Chemicals. $\alpha-\left[1-{ }^{14} \mathrm{C}\right]$ Aminoisobutyric acid $(0.05 \mathrm{Ci} / 0.6 \mathrm{~g})$ and $\mathrm{L}-\left[{ }^{14} \mathrm{C}_{5}\right]$ valine $(200$ $\mathrm{Ci} /$ mole) were purchased from New England Nuclear Corp., L- $\left[{ }^{14} \mathrm{C}_{5}\right]$ proline $(200$ $\mathrm{Ci} /$ mole) and $\mathrm{L}-\left[{ }^{14} \mathrm{C}_{6}\right]$ leucine $(200 \mathrm{Ci} /$ mole $)$ from Isolab Inc., and $\mathrm{L}-\left[\mathrm{Me}^{\left.-{ }^{14} \mathrm{C}\right]-}\right.$ methionine and $\left[1-{ }^{14} \mathrm{C}\right]$ glycine $(45 \mathrm{Ci} /$ mole $)$ from Daiichi Pure Chemicals Co., Ltd. (Japan). Concentrated water solutions of these radioactive amino acids were stocked deep-frozen. Bovine insulin (crystalline, 24 I.U./mg) and $N$-ethylmaleimide were purchased from Sigma Chemical Co., cycloheximide (Acti-dione) from Nutritional Biochemicals Corp., and puromycin dihydrochloride from the American Cyanamide Company.

Animal and tissue preparation. Sprague Dawley rats of body weight ranging from $60-75 \mathrm{~g}$ were sacrificed after feeding ad libitum, or after fasting overnight in some experiments indicated in the text. Rats were decapitated, the uterus was excised rapidly away from ovary and adjacent tissues, and the two horns were cut apart and slit Jongitudinally. Four horns were put into each $50-\mathrm{ml}$ Erlenmeyer flask, the two horns from each animal being paired between control and experimental flasks.

Incubation and determination of uptake of radioactive amino acids. Tissue preparations were incubated at $37^{\circ} \mathrm{C}$ with $6 \mathrm{ml}$ per flask of preincubation or incubation medium as specified in the results. The medium was Krebs-Ringer bicarbonate salt solution or modifications of it made by replacing all of the $\mathrm{Na}^{+}$with choline ions. The gas phase was $95 \% \mathrm{O}_{2}-5 \% \mathrm{CO}_{2}$. Other additions to the medium for various experiments included insulin $(0.11 . \mathrm{U} . / \mathrm{ml})$, puromycin $(0.12 \mathrm{mM})$, cycloheximide $(0.5 \mathrm{mM})$ or $N$-ethylmaleimide $(1$ or $0.05 \mathrm{mM})$. In the incubation for the measurement of the amino acid uptake, radioactive amino acid was added to a level of $0.02-0.04$ $\mu \mathrm{Ci} / \mathrm{ml}$, and to a total concentration of $1.0 \mathrm{mM}$ unless otherwise mentioned. Extraction of the free amino acid in the tissue after incubation was performed as previously [13]. Aliquots of the extract and incubation medium were analyzed by liquid scintillation counting.

Calculation of the intracellular amino acid concentration was made on the bases of the total water content and the extracellular space of the tissue, determined as described earlier $[13,17]$. The water content and the extracellular space of the tissues were obtained in the preliminary experiments for uteri of the ages used (3-4 weeks old) incubated for various periods, and under the conditions of treatment with the hormone and the inhibitors studied in the present work. Statistical analyses were carried out by the calculation of values for paired or non-paired samples, as appropriate. 


\section{RESULTS}

\section{Insulin effect on the uptake of $\alpha$-aminoisobutyric acid and its kinetics}

Fig. 1 shows the time course of uptake of $\alpha$-aminoisobutyric acid by the uterus over $50 \mathrm{~min}$ in both the presence and absence of insulin. Stimulation of $\alpha$-aminoisobutyric acid uptake by insulin appeared at $30 \mathrm{~min}$ of incubation, with a value of $23 \%$ above the control $(P<0.01)$, and was maintained thereafter. Insulin stimulation could be shown in 10-min uptakes, however, if the tissue was incubated with hormone for $20 \mathrm{~min}$ or more before amino acid was added (Table I). 50-min of preincubation without insulin, however, could not be substituted for periods of preincubation with insulin (Expt IV, Table I); and a somewhat smaller effect was found if the insulin was omitted from the final incubation medium (compare Expts III and V). These findings indicate that approximately $20 \mathrm{~min}$ of pretreatment with insulin is essential for the subsequent stimulation of $\alpha$-aminoisobutyric acid uptake by the hormone.

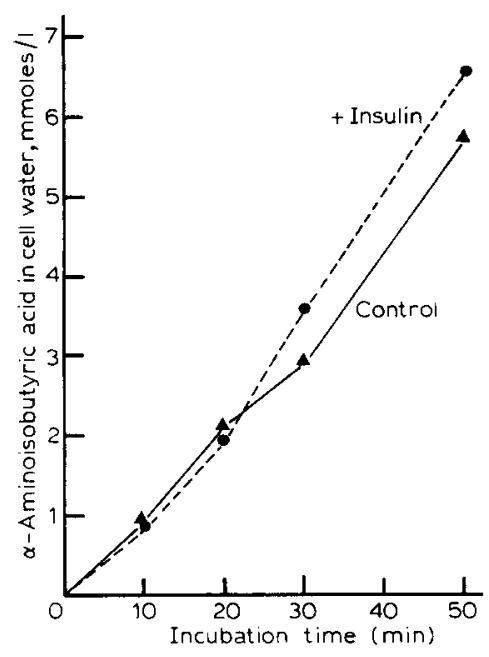

Fig. 1. The insulin effect on the $\alpha$-aminoisobutyric acid uptake by the uterus. Each two uteri, cut into horns and paired, were incubated in $6 \mathrm{ml}$ of Krebs-Ringer bicarbonate solution with labeled $\alpha$-aminoisobutyric acid at an initial concentration of $1.0 \mathrm{mM}$ in the presence or absence of insulin (0.1 I.U./ml) for the periods indicated. Each point shows the mean of the intracellular concentration for $\alpha$-aminoisobutyric acid for 3-9 replications.

Kinetic constants of transport were obtained with the uterus incubated for $10 \mathrm{~min}$ with varying concentrations of $\alpha$-aminoisobutyric acid after $50 \mathrm{~min}$ of preincubation in the presence and absence of insulin. The uterine samples ( 3 or more replications) were paired between the control and the insulin-treated groups. The nonsaturable entry of $\alpha$-aminoisobutyric acid was estimated to be $0.435 / \mathrm{h}$ for both control and insulin-treated uteri by the procedure of Akedo and Christensen [3]. The values of $K_{\mathrm{m}}, 1.28$ and $1.23 \mathrm{mM}, V, 12.4$ and $14.8 \mathrm{mmoles} \cdot \mathrm{l}^{-1} \cdot \mathrm{h}^{-1}$ for the saturable transport in control and insulin-treated uterus, respectively, show that the change of $V$ rather than that of $K_{\mathrm{m}}$ may be responsible for the increase of $\alpha$-aminoisobutyric acid uptake induced by insulin treatment in the uterus (Fig. 2). 


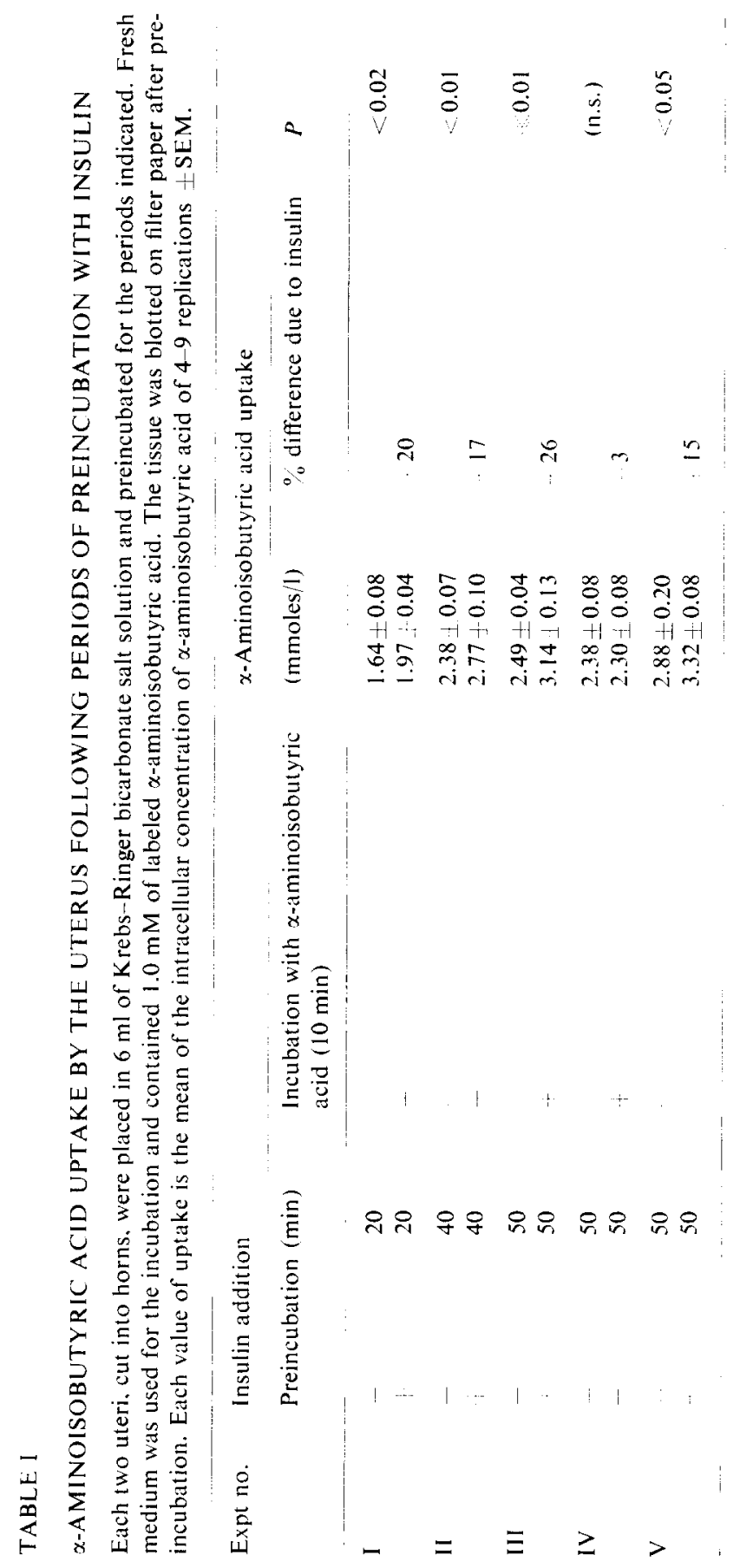




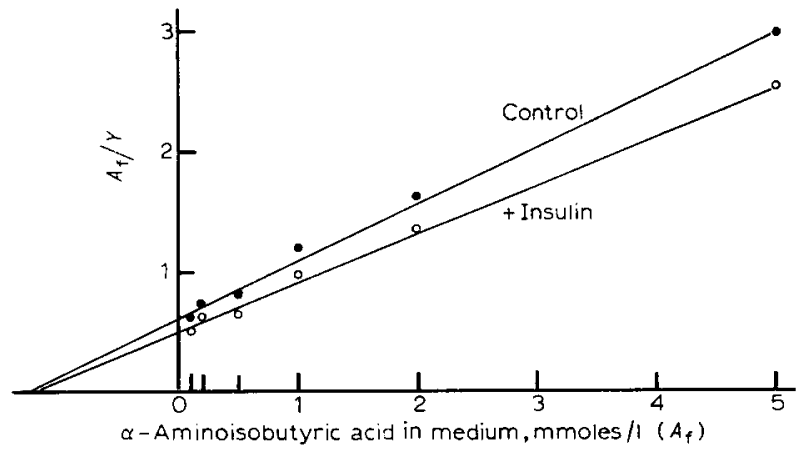

Fig. 2. The insulin effect on the kinetics of the saturable transport of $\alpha$-aminoisobutyric acid. Each four uterine horns, paired between the control and insulin treatment, were preincubated for $50 \mathrm{~min}$ and incubated for $10 \mathrm{~min}$ with $\alpha$-aminoisobutyric acid in Krebs-Ringer bicarbonate solution with or without insulin. Migration of $\alpha$-aminoisobutyric acid into the uterus was assumed to consist of the saturable and non-saturable fractions, and the following equation was proposed for the total uptake of the amino acid (cf. [3]).

$\mathrm{d} A_{\mathrm{c}} / \mathrm{d} t=Y+K_{\mathrm{D}}\left(A_{\mathrm{f}}-A_{\mathrm{c}}\right)$

$A_{\mathrm{c}}$ and $A_{\mathrm{f}}$ show the intra- and extracellular concentrations (mmoles/1), respectively, and $Y$ (mmoles/l of cell water $/ \mathrm{h}$ ) the velocity of uptake by the saturable process. $K_{\mathrm{D}}$ is defined as a rate constant for the non-saturable process and was estimated as $0.435 / \mathrm{h}$, common to the control and insulin-stimulated uptake of $\alpha$-aminoisobutyric acid, by the procedure of Akedo and Christensen [3]. The values of $Y$ or $A_{\mathrm{f}} / Y$ were calculated in varying concentrations of $\alpha$-aminoisobutyric acid in medium using the value of $K_{\mathrm{D}}$. Each point is the average of the values of 3 or more replications.

\section{TABLE II}

\section{INFLUENCE OF PUROMYCIN ON THE INSULIN STIMULATION OF $\alpha$-AMINOISOBU- TYRIC ACID UPTAKE BY THE UTERUS}

Each four horns of the uterus, paired between two groups in each experiment, were placed in $6 \mathrm{ml}$ of preincubation or incubation medium. Rats were fasted overnight before sacrifice. The dotted line shows the addition of neither insulin nor puromycin. See legends of Table 1 for other conditions.

\begin{tabular}{|c|c|c|c|c|c|c|c|}
\hline \multirow{4}{*}{$\begin{array}{l}\text { Expt no. } \\
\overline{\text { VI }}\end{array}$} & \multicolumn{4}{|l|}{ Addition } & \multicolumn{2}{|c|}{$\alpha$-Aminoisobutyric acid uptake } & \multirow[t]{2}{*}{$P$} \\
\hline & \multicolumn{2}{|c|}{ Preincubation (min) } & \multicolumn{2}{|c|}{ Incubation (min) } & \multirow{2}{*}{$\frac{\text { mmoles } / 1}{2.35 \pm 0.10}$} & \multirow[t]{2}{*}{$\%$ difference } & \\
\hline & - & 10 & - & 30 & & & (n.s.) \\
\hline & Puromycin & 10 & Puromycin & 30 & $2.29 \pm 0.13$ & -3 & \\
\hline \multirow[t]{2}{*}{ VII } & - & 10 & Insulin & 30 & $2.74 \pm 0.13$ & & $\ll 0.01$ \\
\hline & Puromycin & 10 & $\begin{array}{l}\text { Insulin } \\
+ \text { puromycin }\end{array}$ & 30 & $2.20 \pm 0.14$ & -20 & \\
\hline \multirow[t]{2}{*}{ VIII } & - & 50 & - & 10 & $1.28 \pm 0.06$ & & $<0.05$ \\
\hline & Puromycin & 50 & Puromycin & 10 & $1.14 \pm 0.02$ & -11 & \\
\hline \multirow[t]{3}{*}{ IX } & Insulin & 50 & Insulin & 10 & $1.41 \pm 0.10$ & & 0.02 \\
\hline & Insulin & & Insulin & & & -3 & \\
\hline & Purami & & & & & & $(n ;)$ \\
\hline \multirow{2}{*}{$x$} & Puromycin & 60 & $\begin{array}{l}\text { Insulin } \\
+ \text { puromycin }\end{array}$ & 30 & $2.05 \pm 0.05$ & & (n.s.) \\
\hline & Puromycin & 60 & Puromycin & 30 & $2.04 \pm 0.11$ & & \\
\hline
\end{tabular}




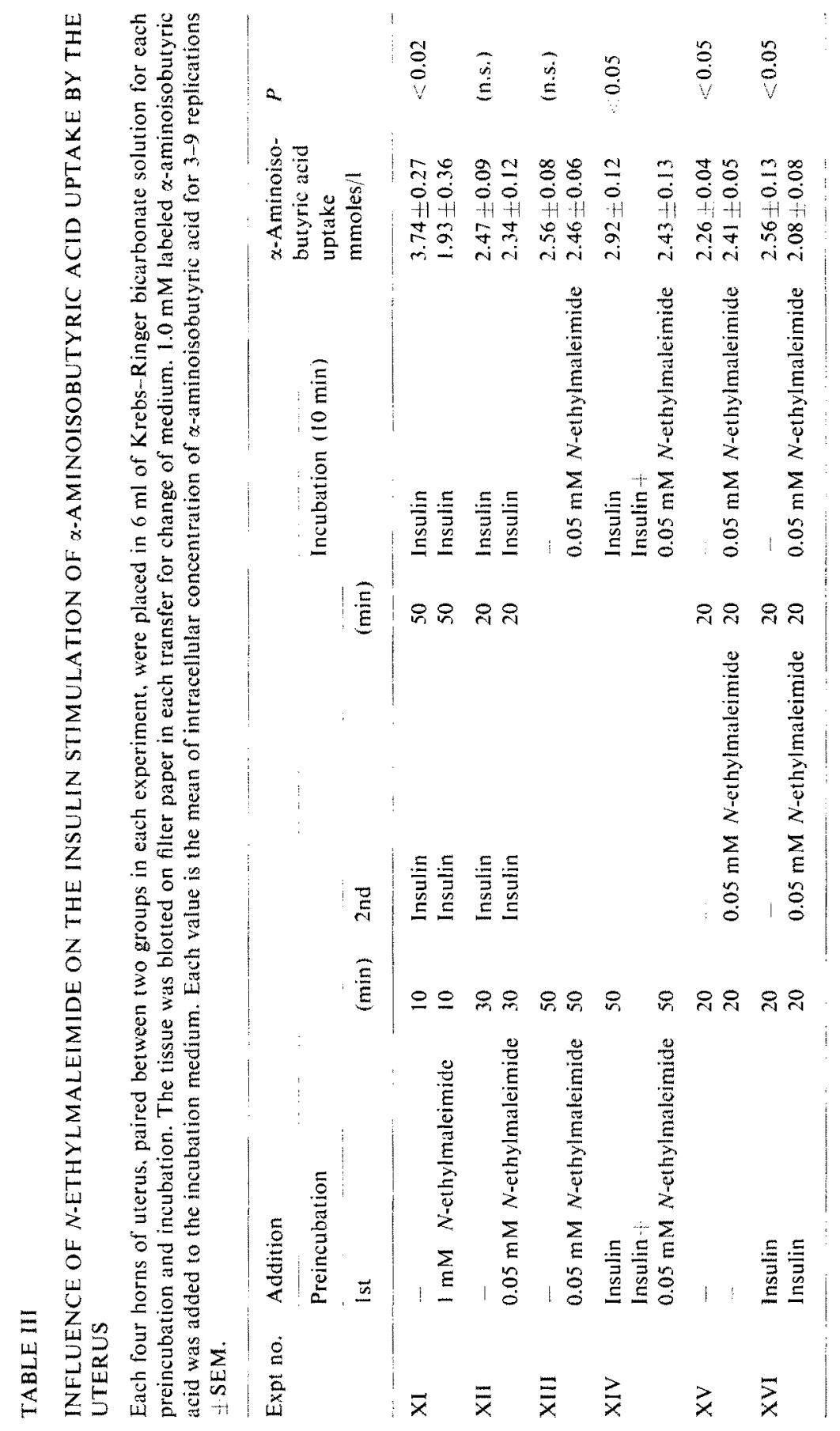


Influence of puromycin on $\alpha$-aminoisobutyric acid uptake and action of insulin

Puromycin inhibited the insulin stimulation of $\alpha$-aminoisobutyric acid uptake when it was present for 40 min over successive preincubation and incubation periods; it did not alter the basal uptake of $\alpha$-aminoisobutyric acid (Expts VI and VII, Table II). Inhibition in both basal and insulin-stimulated uptake appeared, however, when puromycin was present for a total of $60 \mathrm{~min}$ of preincubation and incubation (Expts VIII and IX). The insulin effect was completely abolished when the uterus was incubated in the presence of puromycin for a total of $60 \mathrm{~min}$ of preincubation and 30 min incubation (Expt X). The ability of insulin to stimulate proline uptake (Table IV) was also abolished by the presence of cycloheximide added at the same time as insulin over a 50 -min preincubation period followed by a 10 -min proline uptake.

\section{Influence of $N$-ethylmaleimide on $\alpha$-aminoisobutyric acid uptake and insulin action}

Pretreatment of the uterus with $1 \mathrm{mM} \mathrm{N}$-ethylmaleimide for $10 \mathrm{~min}$ completely suppressed the stimulatory effect of insulin on the $\alpha$-aminoisobutyric acid uptake, the uptake by the $N$-ethylmaleimide-treated tissue being below that normally found in control uteri (Expt XI, Table III). When the uterus was pretreated with a much lower concentration of $N$-ethylmaleimide $(0.05 \mathrm{mM})$ for $30 \mathrm{~min}$, the insulin stimulation was not hampered (Expt XII). But when the tissue was exposed to the low concentration of $N$-ethylmaleimide for $60 \mathrm{~min}$ during the successive preincubation and incubation in the presence of insulin (Expt XIV) or for 30 min during the preincubation after 20 min of insulin treatment (Expt XVI), the stimulation was abolished. The presence of the low concentration of $N$-ethylmaleimide for $60 \mathrm{~min}$ throughout the preincubation and incubation was without effect on the basal uptake by the uterus (Expt XIII). It should be noted that the $\alpha$-aminoisobutyric acid uptake by the tissue was increased somewhat when the low concentration of $N$-ethylmaleimide was present in the medium for $30 \mathrm{~min}$ (Expt XV), but not after $60 \mathrm{~min}$ (Expt XIII).

Separate experiments were carried out to show that the $N$-ethylmaleimide did not produce its effect by binding the insulin in the solution. Ascending paper chromatography of an insulin- $N$-ethylmaleimide mixture, using butanol-acetic acidwater, showed only one spot after it was sprayed with bromcresol green. This spot had the same $R_{\mathrm{F}}(0.08)$ as given by insulin alone. In addition, a mouse bioassay showed the insulin in an insulin- $N$-ethylmaleimide mixture to be as effective as insulin alone in causing skeletal muscle relaxation, ataxia, and convulsions. The results suggest, therefore, that the $N$-ethylmaleimide may have acted by preventing the insulin from binding to the tissue.

\section{Effect of insulin on the uptake of other amino acids}

The uptake of proline and glycine during $10 \mathrm{~min}$ of incubation was increased by about 20 and $63 \%$, respectively, by treatment with insulin for a total of $60 \mathrm{~min}$ of successive preincubation and incubation (Table IV). Methionine uptake was elevated $17 \%$ under these conditions (Table V). The uptake of leucine and valine, however, was not stimulated by the same treatment, either in the presence or absence of an inhibitor of protein synthesis (Table IV). Control uptake of the latter two amino acids was higher than normal in the presence of cycloheximide or puromycin, however (Table IV, Expts XIX-XXII). 


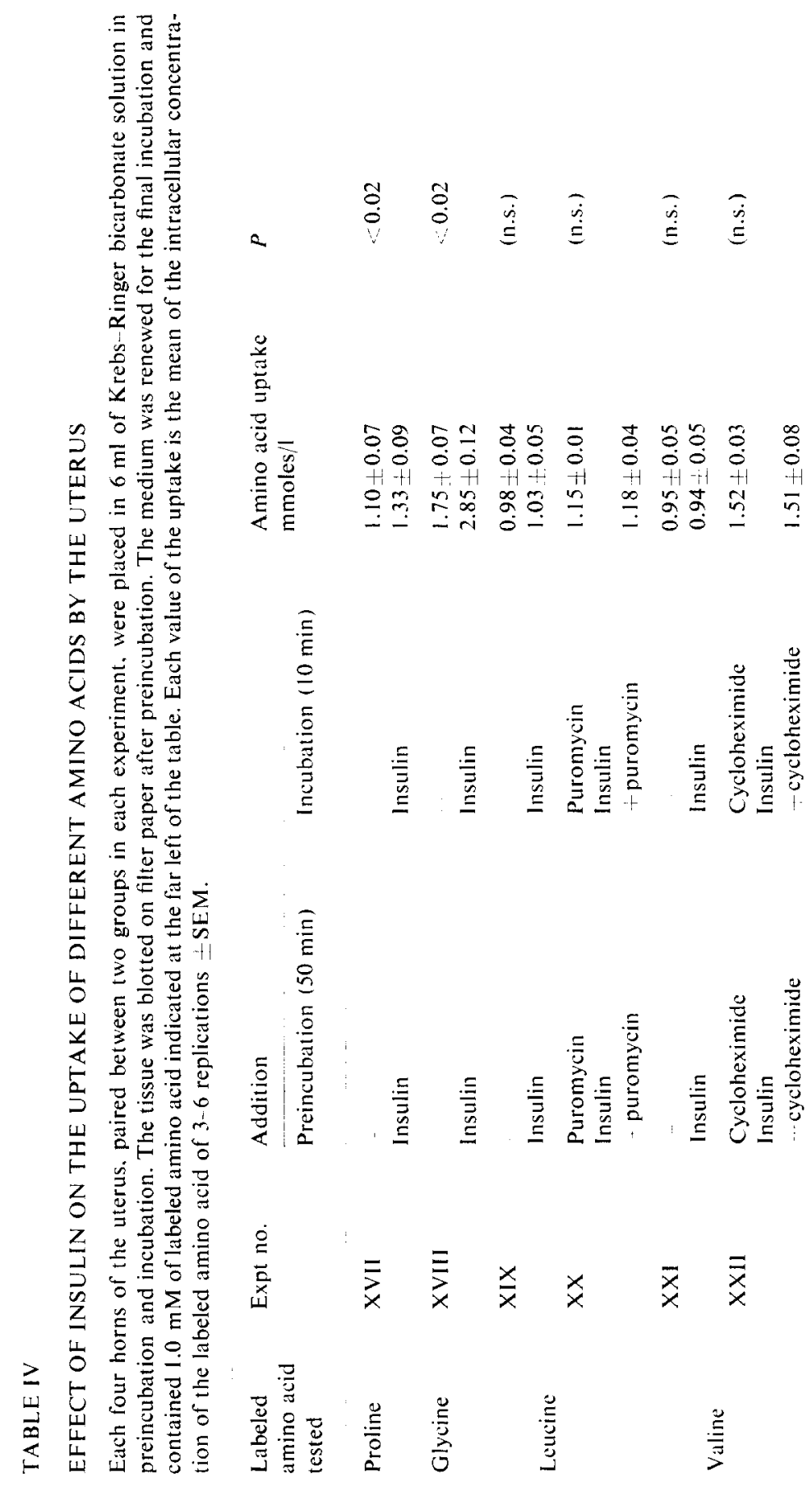




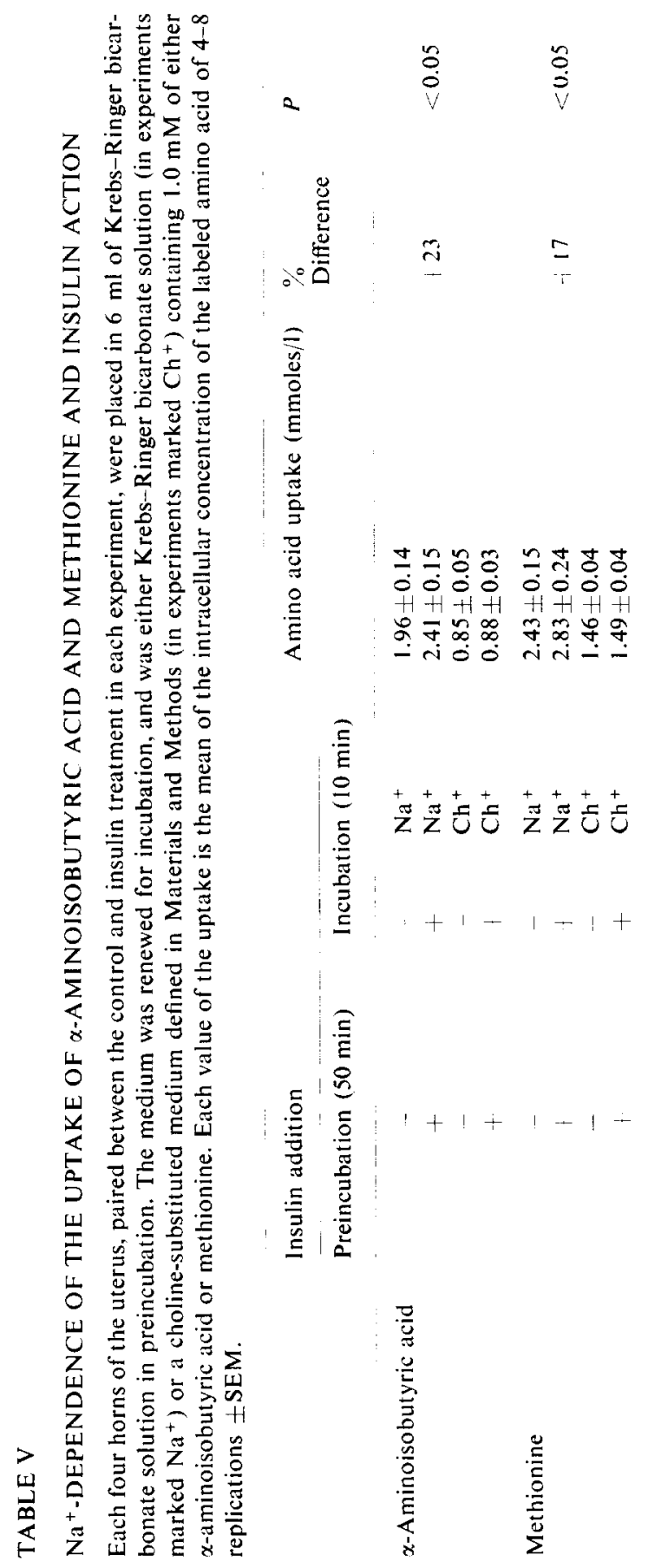


$\mathrm{Na}^{+}$sensitivity of insulin action on amino acid uptake

Replacing the $\mathrm{Na}^{+}$of the medium with choline ion eliminated the insulin stimulation of the uptake of $x$-aminoisobutyric acid and methionine (Table V). In these experiments, normal Krebs-Ringer bicarbonate medium was used for the preincubation with insulin, and the $\mathrm{Na}^{+}$was replaced only during the 10 -min period during which the amino acid was present. It should be noted that methionine was taken up concentratively into the tissue even in the absence of sodium in the incubation medium (Table V).

Effect of insulin on $\alpha$-aminoisobutyric acid transport in the estrogen-primed uterus Since insulin and estradiol showed many characteristics in common in their stimulation of $\alpha$-aminoisobutyric acid uptake, the two hormones were tested together at optimal levels of each. Insulin was added to the incubation medium of uteri taken from rats given $1 \mu \mathrm{g}$ estradiol in vivo $3 \mathrm{~h}$ earlier (a condition shown to give a maximum response in $\alpha$-aminoisobutyric acid uptake [13]). The results are shown in Table VI. A significant increase was given by the insulin, beyond that given by estradiol, whether the insulin was preincubated with the tissue or present during the entire period with $\alpha$-aminoisobutyric acid.

\section{TABLE VI}

EFFECTS OF ESTRADIOL AND INSULIN ALONE AND TOGETHER ON THE $\alpha$-AMINOISOBUTYRIC ACID UPTAKE BY THE IMMATURE UTERUS

Estradiol ( $1 \mu \mathrm{g}$ in $25 \%$ ethanol in saline), or solvent alone was injected intraperitoneally into rats $3 \mathrm{~h}$ before the uteri were removed. Experiment A: All tissues were preincubated for 50 min before the $\alpha$ aminoisobutyric acid uptake was measured for $10 \mathrm{~min}$. Samples with insulin contained $0.1 \mathrm{I} . \mathrm{U} . / \mathrm{ml}$ during both periods. Experiment B: The $\alpha$-aminoisobutyric acid uptake was measured for $60 \mathrm{~min}$. The insulin was present at $0.8 \mathrm{I} . \mathrm{U} . / \mathrm{ml}$ over the entire period. $\alpha$-Aminoisobutyric acid was at $1 \mathrm{mM}$ in each case. There were 4-12 values per group.

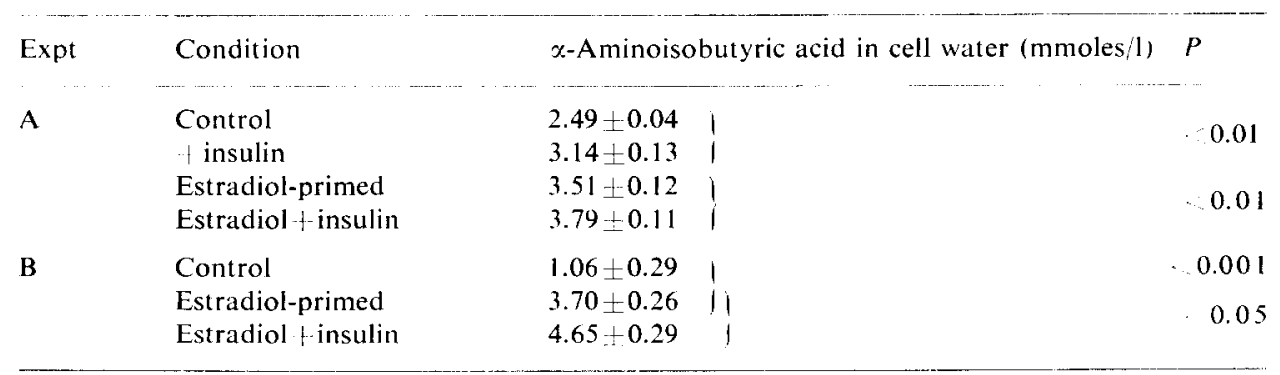

\section{DISCUSSION}

The above results show that insulin significantly increases the short-term uptake of $\alpha$-aminoisobutyric acid, proline, methionine and glycine by the immature rat uterus in vitro. All of these amino acids have been found to have largely $\mathrm{Na}^{+}-$ dependent transport in tissues [18] (cf. [15]). On the other hand, uptake by the uterus of leucine and valine, which prefers consistently a $\mathrm{Na}^{+}$-independent system for transport in Ehrlich ascites tumor cells $[18,19]$ and in the rat uterus [15], was not affected by treatment with insulin. The $\mathrm{Na}^{+}$-independent component of the methion- 
ine transport, on the other hand, was not accelerated by insulin. From these results, it is reasonable to conclude that insulin differentially accelerates the $\mathrm{Na}^{+}$-dependent transport of amino acids in the uterus.

The action of the hormone, on the other hand, was found only after a lag of $20 \mathrm{~min}$ or so, and this time could not be shortened by preincubation without insulin for as long as $50 \mathrm{~min}$. Insulin-stimulated uptake of $\alpha$-aminoisobutyric acid was blocked preferentially to give control values by the simultaneous presence of puromycin for $40 \mathrm{~min}$. In addition, the hormone produced an increase in the $V$ of $\alpha$-aminoisobutyric acid uptake without altering the $K_{\mathrm{m}}$. Although the change in $V$ was small, it appears to account for the increased uptake produced by the hormone, since other transport parameters were not altered. These facts taken together suggest that insulin acted on the transport by increasing the synthesis of one or more proteins of the A system in the uterus.

The action of insulin on amino acid transport in the uterus appears to be similar to that in the diaphragm [16], in that the hormone acts on the A system in both tissues. Several major differences are found, however, a fact that suggests different mechanisms of action. First, a lag of more than 20 min occurred before stimulation in the uterus was initiated, while the increase induced in the diaphragm was apparent in as short a time as $5 \mathrm{~min}$ [20]. The lag time in the uterus, one may speculate, could be the time needed to form new protein of the transport system. Such an interpretation is also consistent with the finding that insulin alters the $V$ of $\alpha$-aminoisobutyric acid uptake in the uterus, a fact suggesting the formation of an increased amount of a protein component of the carrier system. For the diaphragm, in contrast, it seems unlikely that insulin alters the amino acid transport by increasing the protein synthesis (see discussion in [21], [22]), but instead the hormone apparently alters the affinity between amino acid and carrier [3, 10].

The results with $N$-ethylmaleimide also add evidence regarding the possible mechanism by which insulin increases the transport in the uterus. A relatively low concentration of the agent, $0.05 \mathrm{mM}$, blocked the insulin-stimulated $\alpha$-aminoisobutyric acid uptake, regardless of whether it was added at the same time as insulin, or subsequent to treatment with the hormone. The same treatment with $N$-ethylmaleimide produced no effect on the basal $\alpha$-aminoisobutyric acid uptake, a result consistent with earlier work from this laboratory [23]. $N$-ethylmaleimide did not act, however, by binding with the insulin itself in the medium. These findings suggest that the sulfhydryl groups of the uterus are essential for the action of insulin on amino acid transport. We concluded earlier [23] that $N$-ethylmaleimide alters the amino acid transport by binding to the uterus. Also, the uptake in the presence of insulin is more sensitive than normal to $N$-ethylmaleimide. A similar increased sensitivity to $N$-ethylmaleimide was also found for the estradiol-primed uterus [23]. Estradiol $[13,15]$ and insulin both appear to increase the activity of the A system; the action of $N$-ethylmaleimide on the A system is inhibitory [23]. It is, therefore, not surprising that the insulin-stimulated uterus should also show a greater sensitivity to $N$-ethylmaleimide than given by normal tissue. A $0.05 \mathrm{mM}$ level of $N$-ethylmalcimide, used in these experiments, was shown before not to inhibit control $\alpha$-aminoisobutyric acid uptake, while a $1 \mathrm{mM}$ level did [23] (cf. Table III).

Mention should also be made of the fact that a $0.05 \mathrm{mM}$ level of $N$-ethylmaleimide produced a small stimulation in the $\alpha$-aminoisobutyric acid uptake when 
a 30-min exposure was used (Expt XV, Table III). This fact suggests that $\alpha$-aminoisobutyric acid may be transported to a significant extent by the L system (or some other $N$-ethylmaleimide-sensitive system) in the uterus, since this latter system is sensitive to stimulation by $\mathrm{SH}$ agents [23].

Insulin and estradiol show many common characteristics in their actions on amino acid transport in the uterus. Mention has already been made of their response to $\mathrm{N}$-ethylmaleimide. In addition, both hormones appear to act on the $\mathrm{Na}^{+}$-sensitive A system; in both cases the increase is associated with an elevated $V$ with no change in $K_{\mathrm{m}}$ [13]. A lag period of $30-60 \mathrm{~min}$ is needed for the action of estradiol given in vivo $[13,24,25]$, while a similar delay is seen in the effect of insulin added in vitro. The stimulatory actions of both hormones can also be inhibited by the inhibition of protein synthesis [25]. These results suggest that insulin and estradiol may have some common biochemical effect on at least one step in the transport. Nevertheless, some difference in their actions is suggested by the fact that insulin can produce a significant increase in the uptake in uteri in which $\alpha$-aminoisobutyric acid transport has been maximally stimulated by estradiol (Table VI).

\section{ACKNOWLEDGEMENT}

This work was supported in part by grant AM-3709, National Institutes of Health, United States Public Health Service; and by a grant from the Inohana Fund for Medical Sciences, Chiba, Japan.

\section{REFERENCES}

1 Kipnis, D. M. and Noall, M. W. (1965) Biochim. Biophys. Acta 28, 226-227

2 Manchester, K. L. and Young, F. G. (1960) Biochem. J. 75, 487-495

3 Akedo, H. and Christensen, H. N. (1962) J. Biol. Chem. 237, 118-122

4 Fritz, G. R. and Knobil, E. (1963) Nature 200, 682

5 Castles. J. J. and Wool, I. G. (1964) Biochem. J. 91, 11 c-13c

6 Wool, I. G. (1964) Nature 202, 196-197

7 Wool, I. G., Castles, J. J. and Moyer, A. N. (1965) Biochim. Biophys. Acta 107, 333-345

8 Scharff, R. and Wool, I. G. (1965) Biochem. J. 97, 272-276

9 Elsas, L. J., Albrecht, I., Koehne, W. and Rosenberg, L. E. (1967) Nature 214, 916-917

10 Elsas, L. J., Albrecht, I. and Rosenberg, L. E. (1968) J. Biol, Chem. 243, 1846-1853

11 Guidotti, G. G., Borghetti, A. F., Gaja, G., Loreti, L., Ragnotti. G. and Foa. P. P. (1968) Biochem. J. $107,565-574$

12 Guidotti, G. G., Gaja, G., Loreti, L., Ragnotti, G., Rottenberg, D. A. and Borghetti, A. F. (1968) Biochem. J. 107, 575-580

13 Riggs, T. R., Pan, M. W. and Feng. H. W. (1968) Biochim. Biophys. Acta 150, 92-103

14 Riggs, T. R. and Pan, M. W. (1972) Biochem. J. 128, 19-27

15 Riggs, T. R., Pan, M. W. and Feng. H. W. (1972) J. Biol. Chem. 247, 7128-7134

16 Riggs, T. R. and McKirahan, K. J. (1973) J. Biol. Chem. 248. 6450-6455

17 Sorbo, B. (1958) Biochim. Biophys. Acta 27, 324-329

18 Christensen, H. N. (1969) Advances in Enzymol. 32, 1-20

19 Oxender, D. L. and Christensen, H. N. (1963) J. Biol. Chem. 238, 3686-3699

20 Kostyo. J. L. (1968) Ann. N.Y. Acad. Sci. 148, 389-407

21 Wool, I. G. (1968) in Protein and Polypeptide Hormones (Margoulies, M., ed.) pp. 285-295 Excerpta Medica Foundation, Amsterdam

22 Riggs, T. R. (1970) in Biochemical Actions of Hormones (Litwack, G., ed.), Vol. I, pp. 157-208 Academic Press, New York

23 Feng, H. W. and Riggs, T. R. (1973) Biochim. Biophys. Acta 318, 426-438

24 Noall. M. W. and Allen, W. M. (1961) J. Biol. Chem. 236, 2987-2990

25 Roskoski, Jr, R. and Steiner. D. F. (1967) Biochim. Biophys. Acta 135, 347-349 